\title{
Article \\ Cytological Observation and Transcriptome Comparative Analysis of Self-Pollination and Cross-Pollination in Dendrobium Officinale
}

\author{
Yaling Chen ${ }^{*}{ }^{\dagger}$, Benchang $\mathrm{Hu}^{\dagger}{ }^{\dagger}$, Fantao Zhang, Xiangdong Luo and Jiankun Xie \\ College of Life Sciences, Jiangxi Normal University, No 99, Zi Yang Road, Nanchang 330000, China; \\ hubenchang2021@163.com (B.H.); zhang84004@163.com (F.Z.); xdluolf@163.com (X.L.); \\ xiejiankun11@163.com (J.X.) \\ * Correspondence: 005164@jxnu.edu.cn \\ + Yaling Chen and Benchang Hu contributed equally to this work.
}

check for updates

Citation: Chen, Y.; Hu, B.; Zhang, F.; Luo, X.; Xie, J. Cytological Observation and Transcriptome

Comparative Analysis of

Self-Pollination and Cross-Pollination in Dendrobium Officinale. Genes 2021,

12, 432. https://doi.org/10.3390/ genes12030432

Academic Editor: Abdelhafid I. Bendahmane

Received: 20 February 2021

Accepted: 15 March 2021

Published: 17 March 2021

Publisher's Note: MDPI stays neutral with regard to jurisdictional claims in published maps and institutional affiliations.

Copyright: (c) 2021 by the authors. Licensee MDPI, Basel, Switzerland. This article is an open access article distributed under the terms and conditions of the Creative Commons Attribution (CC BY) license (https:/ / creativecommons.org/licenses/by/ $4.0 /)$.

\begin{abstract}
Dendrobium officinale is a rare and traditional medicinal plant with high pharmacological and nutritional value. The self-incompatibility mechanism of $D$. officinale reproductive isolation was formed in the long-term evolution process, but intraspecific hybridization of different germplasm resources leads to a large gap in the yield, quality, and medicinal value of $D$. officinale. To investigate the biological mechanism of self-incompatibility in D. officinale, cytological observation and the transcriptome analysis was carried out on the samples of self-pollination and cross-pollination in D. officinale. Results for self-pollination showed that the pollen tubes could grow in the style at $2 \mathrm{~h}$, but most of pollen tubes stopped growing at $4 \mathrm{~h}$, while a large number of cross-pollinated pollen tubes grew along the placental space to the base of ovary, indicating that the self-incompatibility of D. officinale may be gametophyte self-incompatibility. A total of $63.41 \mathrm{G}$ basesum of $D$. officinale style samples from non-pollinated, self-pollination, and cross-pollination by RNA-seq were obtained, and a total of 1944, 1758, and 475 differentially expressed genes (DEGs) in the comparison of CK (non-pollinated) vs. HF (cross-pollination sample), CK vs. SF (self-pollination sample) and SF vs. HF were identified, respectively. Forty-one candidate genes related to self-incompatibility were found by function annotation of DEGs, including $6 \mathrm{Ca}^{2+}$ signal genes, 4 armed repeat containing $(A R C)$ related genes, $11 \mathrm{~S}$-locus receptor kinase (SRK) related genes, 2 Exo70 family genes, 9 ubiquitin related genes, 1 fatty acid related gene, 6 amino acid-related genes, 1 pollen-specific leucine-rich repeat extensin-like protein $(L R X)$ related gene and 1 lectin receptor-like kinases $(R L K s)$ related gene, showed that self-incompatibility mechanism of $D$. officinale involves the interaction of multiple genes and pathways. The results can provide a basis for the study of the self-incompatibility mechanism of D. officinale, and provide ideas for the preservation and utilization of high-quality resources of D. officinale.
\end{abstract}

Keywords: Dendrobium officinale; cytological observation; transcriptome; self-incompatibility; genes

\section{Introduction}

Dendrobium officinale Kimura et Migo, belonging to Orchidaceae family, is an ancient and valuable Chinese herbal medicine with high pharmacological and nutritional value, listed as a traditional Chinese herbal in Chinese Pharmacopoeia (State Pharmacopeia Committee of China 2015) [1]. D. officinale is mainly distributed in the southern provinces of China, and it is also in East Asia, Southeast Asia, and Australia [2]. The stems and leaves of $D$. officinale contain a variety of effective active ingredients, such as polysaccharides, flavonoids, and alkaloids, which have important pharmacological and edible effects, including the prevention of aging, immunoregulation, antioxidant, and anti-inflammatory effects [3-5]. Recently, some studies have found that D.officinale also exhibit cure colitis, antiangiogenic, and anti-tumor effects [6-8]. The medicinal value of D. officinale has gradually 
been recognized by the public, and wild $D$. officinale has been exploited to near extinction and is now listed as an IUCN (International Union for Conservation of Nature) critically endangered plant.

In the long-term evolution process, the self-incompatibility mechanism of $D$. officinale reproductive isolation has formed, which shows that the pistils and stamens develop normally and mature at the same time, and the seeds can not be produced after selfpollination or cross-pollination with the same genotype [9,10]. Previous studies have shown that the seed setting rate of self-pollination in D. officinale was lower than $10 \%$, and that of cross-pollination was higher (80 90\%) [11]. The fine varieties of $D$. officinale can only be preserved by intraspecific hybridization or asexual propagation [9]. At present, most of the $D$. officinale in the market are generated through intraspecific hybridization of different germplasm resources, leading to a large gap in the yield, quality, and medicinal value of D. officinale [12-14]. This further caused confusion in the D. officinale market. Therefore, understanding the molecular mechanism of self-incompatibility in $D$. officinale is important for protecting $D$. officinale resources.

Self-incompatibility (SI) is an ancient and common phenomenon which promotes genetic diversity by avoiding self-fertilization in seed plants that possess both stamen and pistil in the same flowers [15]. According to the genetic control modes of pollen SI, it can be divided into two types: sporophytic self-incompatibility (SSI) including Brassicaceae, Asteraceae and Convolvulaceae [16], and gametophytic self-incompatibility (GSI) [17], such as Solanaceae, Scrophyulariaceae, Ranunculaceae, Rosaceae, Onagraceae, Papaveraceae, Leguminosae, and Poaceae [16]. In GSI, incompatibility depends on the haploid genotype of the pollen, whereas in SSI it depends on the diplotype of its parent [17,18]. GSI is a genetic definition and that pathways in GSI are diverse. In GSI, the S-RNases in the style can degrade the RNA in self pollen tube and the $\mathrm{Ca}^{2+}$ mediated pathway are the two most common pathways $[19,20]$. While the SSI response results from the binding between the S-locus cysteine-rich protein (SCR) in pollen and the S-locus receptor kinase (SRK) that exists on the plasma membrane of the stigma. Thus, its pollen is rejected, completing the SI reaction [21-23]. ARC1 (armed repeat containing 1), MLPK (M locus protein kinase), and Exo70A1 (exocyst subunit exo70 family protein A1) are SI-related genes in Brassica and Arabidopsis [24,25]. Additionally, $\mathrm{Ca}^{2+}$ signaling is vital for the process of SSI [26]. Proteomic analyses of pollination in Dendrobium. chrysanthum exhibited that $\beta$-oxidation of fatty acids, amino acid metabolism, oxidative phosphorylation, and ubiquitin-related protein were associated with SI [27].

D. officinale is a perennial epiphytic herbaceous plant of the genus Dendrobium. In previous reports, self-incompatibility of Dendrobium officinale focused on the observation of seed setting rate and cell biology, but the molecular regulation mechanism is still poorly understood. In the present study, cytological observation was carried out on the samples of self-pollination and cross-pollination in order to identify the SI in D. officinale. At the same time, the transcriptome analysis was used to obtain some candidate genes related to SI $D$. officinale. The results can provide a basis for the study of SI mechanism of D. officinale, and provide ideas for the preservation and utilization of high-quality resources of $D$. officinale.

\section{Materials and Methods}

\subsection{Plant Materials and Growth Conditions}

Xie et al. [28] indicated that the origin of market individuals were derived from Shenglan8, and our previous observation showed that Shenglan8 and Longhu1 had high seed setting rate of cross-pollination. So, we selected Shenglan 8 for self-pollination and Shenglan 8 cross-pollination with Longhu1 to explore cytological and transcriptome comparative phenomena of self-pollination and cross-pollination in D. officinale. The tissue-cultured seedlings propagated by stem segments of $D$. officinale were collected from the Jiangxi germplasm resource bank in China. It was cultivated in the laboratory of Jiangxi Normal University. The seedlings were transplanted into pots and cultivated in the growth chamber with a light:dark cycle of $12 \mathrm{~h}$ each at 20 to $25^{\circ} \mathrm{C}$ and a relative humidity of 60 to 
75\%; pine bark was used as the substrate. In May 2019, we conducted self-pollination or cross-pollination with sterilized toothpicks on the 3rd to 5th day of flowering. To observe pollen tube growth, nine styles per each sample were gathered at $0 \mathrm{~h}, 2 \mathrm{~h}, 4 \mathrm{~h}$, and $8 \mathrm{~h}$ after self-pollination, respectively, and also gathered at the same time after cross-pollination, then fixed in FAA (formaldehyde:acetic acid:70\% alcohol in a ratio of 5:5:90) and stored at $-4{ }^{\circ} \mathrm{C}$. For transcriptome sequencing, sixty styles were collected and mixed per each sample that were non-pollinated, self-pollinated ( $4 \mathrm{~h}$ later), and cross-pollinated ( $4 \mathrm{~h}$ later), with three biological duplicates in each group, respectively. The group of non-pollinated samples was labeled as CK (non-pollinated) 1, CK2, CK3; self-pollinated were labeled as SF (self-pollinated)1, SF2, SF3; cross-pollinated were labeled as HF (cross-pollinated) 1, HF2, HF3. All flash-frozen style samples were stored at $-80^{\circ} \mathrm{C}$.

\subsection{Histological Observe of Pollen Tube Growth}

The microscopic paraffin-embedded sections were used to observe pollen tube growth to understand the SI of D. officinale [29]. The specimens were sliced lengthwise along the stigma using the LEICA microtome RM2016 (LEICA, Shanghai, China). The dyeing procedure was as follows. The first step was dewaxing: paraffin sections were dewaxed by incubating the slices in xylene two times for $20 \mathrm{~min}$ each, twice in anhydrous ethanol for $10 \mathrm{~min}$ each, followed by incubation in gradient ethanol $(95 \%, 90 \%, 80 \%$, and $70 \%$ alcohol for $5 \mathrm{~min}$ each) and finally, distilled water. The second step was staining: the sections were stained with a $1 \%$ safranin staining solution for $2 \mathrm{~h}$ and rinsed with tap water. The third step was decolorization: the slices were decolorized using $50 \%, 70 \%$, and $80 \%$ gradient alcohol for $1 \mathrm{~min}$ each. The fourth step was staining with fast green (FCF) stain: the sections were stained with $0.5 \%$ fast green dye solution for 30 to $60 \mathrm{~s}$, followed by decolorization in anhydrous ethanol twice for $30 \mathrm{~s}$ and $1 \mathrm{~min}$, respectively. The fifth step was the preparation of the cover slice: the slices were baked in a $60^{\circ} \mathrm{C}$ oven, kept in xylene solution for $5 \mathrm{~min}$, and finally, the slice was covered with neutral gum. The slices were observed and captured with scanning electron microscope KF-PRO-005 (KFBIO, Ningbo, China).

\subsection{Total RNA Extraction, Library Preparation and Transcriptome Sequencing}

In our study, the styles of non-pollinated, self-pollinated ( $4 \mathrm{~h}$ after pollinated), and cross-pollinated ( $4 \mathrm{~h}$ after pollinated), were ground into powder in mortar with liquid nitrogen, with three biological duplicates in each group, and then the plant rapid extraction kit (Takara, Dalian, China) was used for total RNA extraction from the column samples. The degradation and purity of isolated RNA were studied through $1 \%$ agarosegels electrophoresis and IMPLEN NanoPhotometer ${ }^{\circledR}$ spectrophotometer (IMPLEN, California, CA, USA), respectively. Also, the Qubit ${ }^{\circledR}$ 2.0 Fluorometer (Life Technologies, California, CA, USA) was used for RNA quantification using Qubit ${ }^{\circledR}$ RNA Assay Kit. RNA integrity was tested using the Agilent Bioanalyzer2100 system (Agilent Technologies, California, CA, USA) using the RNA Nano6000 assay kit.

After the RNA sample was qualified using magnetic beads with Oligo (dT), and samples of mRNA enriched by the ways of A-T complementary pairing and binding to the polyA tail of mRNA. Then fragmentation buffer was added to break the mRNA into short fragments. We used mRNA as a template, reverse transcriptase (RNase $\mathrm{H}-$ ) and a random hexamer primer were used to prepare the first strand of cDNA, followed by the subsequent synthesis of the second strand using RNase $\mathrm{H}$ and DNA Polymerase I. Then we used AMPure XP (Beckman Coulter, Beverly, Massachusetts, MA, USA) beads to purify double-stranded cDNA. We performed a purified double-stranded cDNA end repair, added an A tail and connected sequencing adapter, then AMPure XP beads were also used for fragment size selection, and finally, PCR enrichment was performed to obtain the final cDNA library. The cDNA library was sequenced by an Illumina Hiseq2500 platform and $125 / 150$ bp paired-end rawreads were generated. We used in-house perl scripts, and clean reads were generated from the raw reads by removing adapter reads, ploy-N reads, and 
low-quality reads. Additionally, we calculated Q20, Q30, and GC content of the clean data. Further analyses were done using high-quality clean data.

\subsection{Reads Mapping to the Reference Genome}

The genome database (http:/ / herbalplant.ynau.edu.cn, accessed on 16 March 2021) and the genome database (https: / ftp.ncbi.nlm.nih.gov / genomes/all/GCF/001/605/985/ GCF_001605985.2_ASM160598v2/GCF_001605985.2_ASM160598v2_genomic.fna.gz, accessed on 16 March 2021) provided the gene model annotation files and the reference genome. Bowtie (v2.2.3) (default parameter) and TopHat (v2.0.12) (Parameter: mismatch =2) were utilized to build the reference genome index and to align the clean reads to the reference genome, respectively. TopHat was chosen since it was superior to contemporary tools as it could generate a gene model annotation-based splice junction database.

\subsection{Identification of Differentially Expressed Genes (DEGs)}

Gene expression was calculated as reads per kilobase of transcript, per million reads (RPKM). The fragment length and corresponding mapped reads were used to calculate FPKM using Cuffquant and cuffnorm (v2.2.1) in each sample [30]. Here, the summation of FPKMs of transcripts in each gene group for DESeq2 provided the gene expression levels [31]. DESeq2 R package (v 1.10.1) was used to conduct differential expression analysis of two conditions/groups (two biological duplicates/conditions). DESeq2 facilitated the determination of differential gene expression using a negative binomial distribution-based model. The resulting $p$-values were adjusted to account for the FDR, and those with the adjusted $p$-value $<0.01$ were classified as DEGs.

\subsection{Function Annotation and Enrichment Analysis}

In order to know the function of unigene, we used databases including $\mathrm{Nr}$ (ftp: / /ftp.ncbi.nlm.nih.gov/blast/db, accessed on 16 March 2021), Swiss-Prot (http:/ / ftp.ebi. ac.uk/pub/databases/swissprot/, accessed on 16 March 2021), TrEMBL (https:/ /www. uniprot.org/news/2004/03/02/full, accessed on 16 March 2021), KOG (ftp:/ /ftp.ncbi. nih.gov/pub/COG/KOG, accessed on 16 March 2021), Pfam (http://pfam.xfam.org/, accessed on 16 March 2021), GO (http:/ / geneontology.org/, accessed on 16 March 2021), COG (https://www.ncbi.nlm.nih.gov/COG, accessed on 16 March 2021), and KEGG (http:/ / www.genome.jp/ kegg/, accessed on 16 March 2021) to annotate the unigene of transcriptome sequencing and the DEGS. To find the DEGs associated with SI, GO, COG, and KEGG databases were used to function enrich and classify the DEGS of SF vs. HF. The Gene Ontology (GO) seq R package was utilized for GO enrichment analysis of DEGs, which involved the correction of the gene length bias, and those with corrected $p$-value $<0.05$ were regarded as significantly enriched in DEGs. The KEGG database was used for understanding the protein network analysis (http://www.genome.jp/kegg/, accessed on 16 March 2021). We studied the DEGs enriched in KEGG pathways via the KOBAS software (v2.0, Beijing, China).

\section{7. qRT-PCR Validate Analysis}

In this study, we used qRT-PCR to analyze DEGS levels in SF vs. HF to verify the reliability of transcriptome sequencing data. The PrimeScript ${ }^{\mathrm{TM}} \mathrm{RT}$ reagent kit (Takara, Dalian, China) with gDNA Eraser was used for cDNA synthesis. Primer 3.0 (v0.4.0) was utilized for designing the gene primers sequences for qRT-PCR analysis (Supplementary Table S1). The StepOne ${ }^{\mathrm{TM}}$ Real-Time PCR System (ABI, New York, NY, USA) was used to perform qRT-PCR using the $2 \times$ Q3 SYBR qPCR Master mix (TOLOBIO, Shanghai, China). Each experiment was performed in triplicates. The gene expression levels were normalized using the GAPDH gene [32]. Relative quantification of genes expression was calculated based on the $2^{-\Delta \Delta C T}$ method [33]. 


\section{Results}

\subsection{Observation of Pollen Tube Growth}

The growth of pollen tubes in the style at $0 \mathrm{~h}, 2 \mathrm{~h}, 4 \mathrm{~h}, 8 \mathrm{~h}$ after self-pollination and cross-pollination was observed by scanning electron microscope, respectively. Results showed that there are guiding tissues on the pistil stigma (blue arrow), and pollen tubes (black arrow) in the style are clustered together and grow longitudinally along the two walls at $0 \mathrm{~h}$ after self-pollination and cross-pollination (Figure 1A,E). At $2 \mathrm{~h}$ of pollination, the selfpollinated pollen tube grows to the middle of the style, while the cross-pollinated pollen tube grows to the style bottom, and the pollen tubes of cross-pollination are obviously more than those of self-pollination (Figure 1B,F). At $4 \mathrm{~h}$ of pollination, most of the self-pollinated pollen tubes stopped growing and only a few slowly grew to the style bottom (Figure 1C). Although some cross-pollinated pollen tube growth was arrested in the styles, lots of pollen tubes still grew to the style bottom at $4 \mathrm{~h}$ of pollination (Figure 1G). At $8 \mathrm{~h}$ of self-pollination, the pollen tubes that grew to the upper part of the style had disappeared and a few pollen tubes kept growing slowly to the bottom of the style (Figure 1D), while the pollen tubes continue to grow towards the bottom of the ovary, some of them have reached the ovule (red arrow) after cross-pollination (Figure 1H). These observations indicate that the growth of pollen tubes in the style is significantly inhibited after self-pollination in D. officinale.

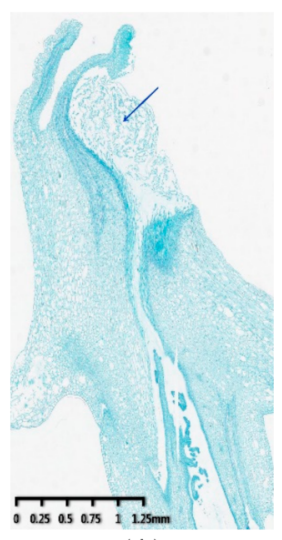

(A)

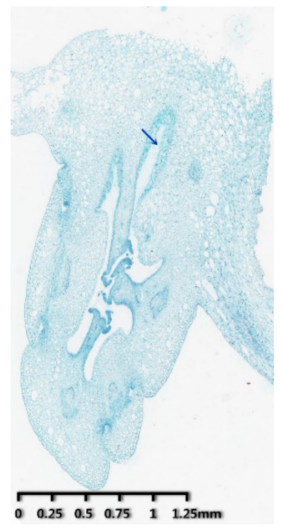

(E)

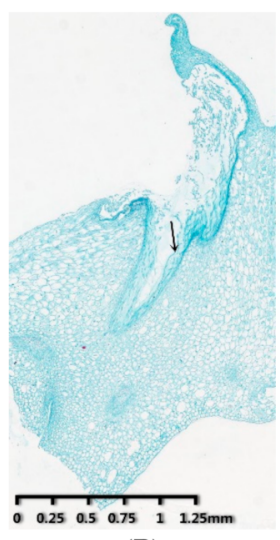

(B)

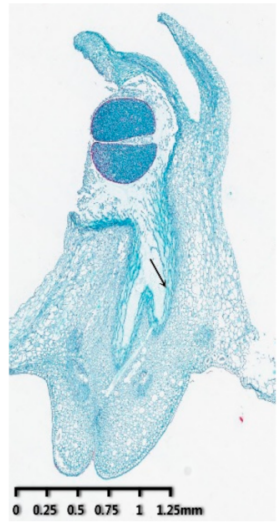

(F)

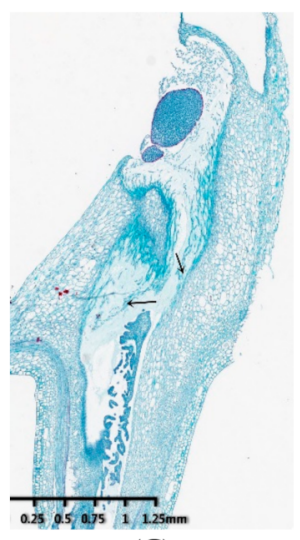

(C)

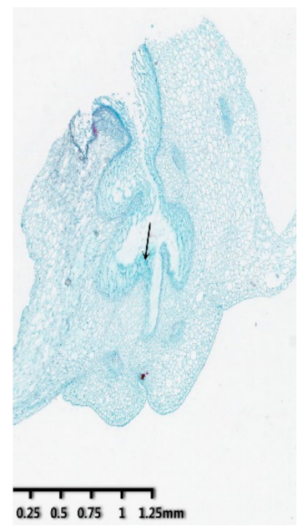

(G)

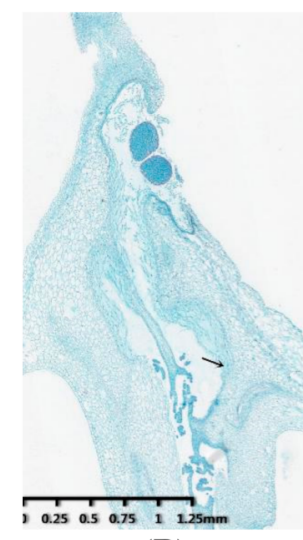

(D)

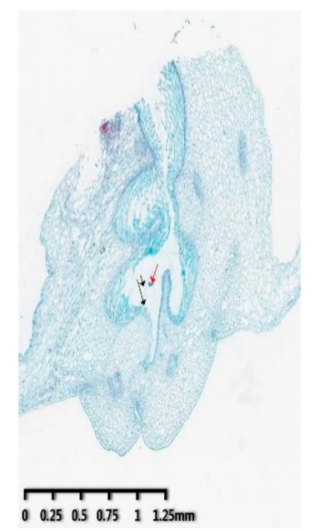

(H)

Figure 1. The growth of pollen tube after self-pollination and cross-pollination in the pistils. (A) The picture of nonpollination in self-pollination. (B) The growth of pollen tube in $2 \mathrm{~h}$ after self-pollination. (C) The growth of pollen tube $4 \mathrm{~h}$ in after self-pollination. (D) The growth of pollen tube $8 \mathrm{~h}$ in after self-pollination. (E) The picture of non-pollination in cross-pollination. (F) The growth of pollen tube in $2 \mathrm{~h}$ after cross-pollination. (G) The growth of pollen tube in $4 \mathrm{~h}$ after cross-pollination. (H) The growth of pollen tube in $8 \mathrm{~h}$ after cross-pollination. The blue arrow point to the stigma, the black arrow point to the pollen tube, and the red arrow point to the ovule. 


\subsection{Transcriptome Sequencing Analysis}

In the present study, non-pollinated, self-pollinated (4 $\mathrm{h}$ later), and cross-pollinated (4 h later) column samples were collected to perform RNA-seq analysis. Three groups of cDNA libraries (non-pollinated: CK1, CK2, CK3; self-pollination: SF1, SF2, SF3; crosspollination: HF1, HF2, HF3) were separately prepared. In this study, the raw data contained 63,409,511,100 baseSum. After removing the low-quality sequences, we obtained $211,365,037$ readSum. The average Q20, Q30 values, and GC content was $97.56 \%, 93.24 \%$, and $47.63 \%$, respectively (Table 1 ). Thus, the data of the transcriptome sequencing had high stability. In addition, $71.58 \%$ of the clean reads were mapped to the reference genome (Table 2). Through this result, it can be evaluated that the selected reference genome assembly can meet the needs of information analysis.

Table 1. The information of the sequenced transcriptome in Dendrobium officinale.

\begin{tabular}{cccccc}
\hline \#Sample ID & ReadSum & BaseSum & GC(\%) & Q20(\%) & Q30(\%) \\
\hline CK1 & $22,450,889$ & $6,735,266,700$ & $47.49 \%$ & $97.83 \%$ & $93.76 \%$ \\
CK2 & $21,276,069$ & $6,382,820,700$ & $47.25 \%$ & $97.14 \%$ & $92.14 \%$ \\
CK3 & $24,726,730$ & $7,418,019,000$ & $47.09 \%$ & $97.46 \%$ & $92.97 \%$ \\
CK average & $22,817,896$ & $6,845,368,800$ & $47.28 \%$ & $97.48 \%$ & $92.96 \%$ \\
HF1 & $28,969,506$ & $8,690,851,800$ & $52.62 \%$ & $97.29 \%$ & $92.85 \%$ \\
HF2 & $20,949,503$ & $6,284,850,900$ & $47.06 \%$ & $97.64 \%$ & $93.40 \%$ \\
HF3 & $21,063,503$ & $6,319,050,900$ & $46.80 \%$ & $97.74 \%$ & $93.63 \%$ \\
HF average & $23,660,837$ & $7,098,251,200$ & $48.83 \%$ & $97.56 \%$ & $93.29 \%$ \\
SF1 & $20,991,442$ & $6,297,432,600$ & $46.87 \%$ & $97.71 \%$ & $93.55 \%$ \\
SF2 & $27,714,690$ & $8,314,407,000$ & $46.88 \%$ & $97.60 \%$ & $93.33 \%$ \\
SF3 & $23,222,705$ & $6,966,811,500$ & $46.65 \%$ & $97.65 \%$ & $93.49 \%$ \\
SF average & $23,976,279$ & $7,192,883,700$ & $46.80 \%$ & $97.65 \%$ & $93.46 \%$ \\
Total average & $23,485,004$ & $7,045,501,233$ & $47.63 \%$ & $97.56 \%$ & $93.24 \%$ \\
Total & $211,365,037$ & $63,409,511,100$ & & & \\
\hline
\end{tabular}

Sample ID: sample name; ReadSum: clean data total number of pair-end Reads; BaseSum: clean data total base number; GC (\%): clean data GC content, clean data G and C bases account for total alkali percentage of base Q20 (\%): a sequencing error probability of $1 \%$; Q30 (\%): a sequencing error probability of $0.1 \%$.

Table 2. The table of the sequence alignment between sequencing data and the reference genome.

\begin{tabular}{ccc}
\hline Sample ID & Total Read & Reads Mapped \\
\hline CK1 & $44,901,778$ & $33,273,053(74.10 \%)$ \\
CK2 & $42,552,138$ & $31,039,066(72.94 \%)$ \\
CK3 & $49,453,460$ & $34,715,952(70.20 \%)$ \\
HF1 & $57,939,012$ & $39,336,622(67.89 \%)$ \\
HF2 & $41,899,006$ & $29,965,533(71.52 \%)$ \\
HF3 & $42,127,006$ & $30,322,911(71.98 \%)$ \\
SF1 & $41,982,884$ & $30,649,680(73.01 \%)$ \\
SF2 & $55,429,380$ & $40,043,108(72.24 \%)$ \\
SF3 & $46,445,410$ & $33,240,722(71.57 \%)$ \\
Total & $422,730,074$ & $302,586,647(71.58 \%)$
\end{tabular}

Sample ID: Sample name; Total read: The number of Clean Reads is counted as two Reads in one pair; Reads mapped: The number of Reads mapped to the reference genome and the percentage of Reads in Clean Reads.

Previous studies have clarified that there are biological differences in gene expression among different individuals [34]. Thus, for studies involving biological duplicates, it is necessary to assess their relevance to analyze transcriptome sequencing data. Here, we used Pearson's correlation coefficient $\left(\mathrm{R}^{2}\right)$ as an indicator of biological repeat correlation [35]. All $R^{2}$ values were $>0.78$ amongst different biological duplicates and were $>0.55$ between different samples (Supplementary Figure S1). In addition, we analyzed all of samples gene expression clustering and we found insignificant differences among the duplicated samples and groups from the heat map (Supplementary Figure S2).

The unigenes in three transcriptome sequencing databases were annotated in the databases (a total of 38,373 unigenes). These unigenes were annotated in public databases 
including Nr, Swiss-Prot, TrEMBL, Pfam, KOG, GO, COG, and KEGG databases. Among them, there were 38,343 unigenes in $\mathrm{Nr}$ database, accounting for $99.92 \%, 35,450$ unigenes in TrEMBL database, accounting for $92.38 \%$ and 27,694 comments in Swiss-Prot database, accounting for $72.17 \%$, respectively. A total of 26,003 unigenes annotated in Ptam databases, accounting for $67.76 \%$. The numbers of unigenes in KOG databases 22,346 (accounting for 58.28\%). Besides, 15,993 unigenes (accounting for $41.68 \%$ ) annotated in GO databases, 10,665 unigenes (accounting for 27.80\%) annotated in COG database, 6775 unigenes (accounting for $17.66 \%$ ) annotated in KEGG databases, respectively (Supplementary Figure S3), showed that many metabolic pathways are involved in self- and cross-pollinated of D. officinale.

\subsection{Identification of Differentially Expressed Genes (DEGs)}

We used FDR (false discovery rate) $<0.01$ and $\log _{2}$ FC (fold Change) $\geq 2$ as the selection parameters to identify DEGs. The fold Change implied the expression ratio between the two sample groups. The FDR was achieved by correcting the difference for significant $p$-values. Here, the comparison of CK1_CK2_CK3_vs._HF1_HF2_HF3, CK1_CK2_CK3_vs._SF1_SF2_SF3, and SF1_SF2_SF3_vs._HF1_HF2_HF3 yielded 1944, 1758, and 475 DEGs, respectively (Table 3 and Supplementary Figure S4). Of these, nine genes were commonly expressed in the $\mathrm{CK}, \mathrm{SF}$, and HF libraries based on the Venn diagram (Figure 2A). Amongst the detected DEGs, the CK1_CK2_CK3_vs_HF1_HF2_HF3 group had 1358 upregulated and 586 downregulated genes (Figure 2B), the CK1_CK2_CK3_vs. SF1_SF2_SF3 group had 932 up-regulated and 826 down-regulated genes (Figure 2C), and the SF1_SF2_SF3_vs._HF1_HF2_HF3 group had 417 up-regulated and 58 down-regulated genes (Figure 2D). Particularly, the SF1_SF2_SF3_vs._HF1_HF2_HF3 group had fewer DEGs than the other two groups.

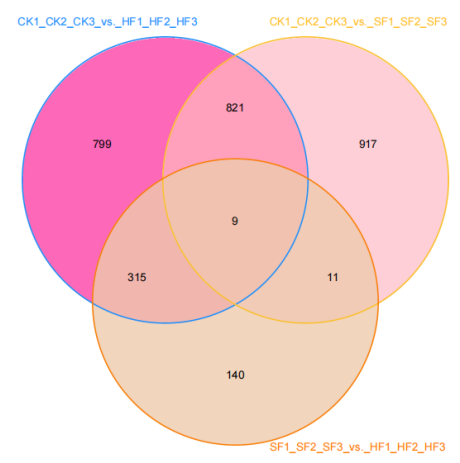

(A)

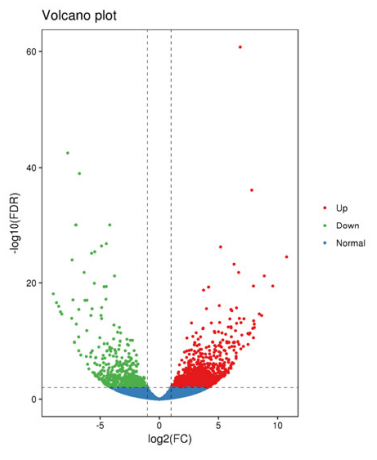

(B)

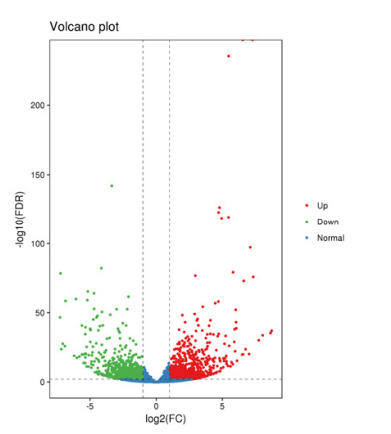

(C)

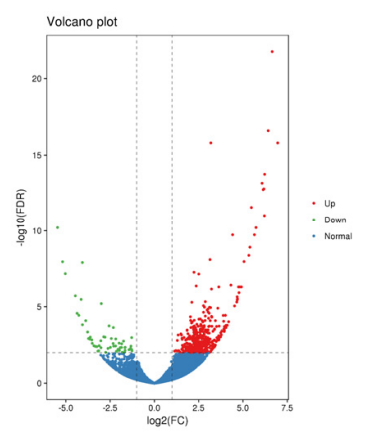

(D)

Figure 2. Statistics of genes with differential expressions in the CK1, CK2, CK3; HF1, HF2, HF3; SF1, SF2, SF3 libraries. (A) Venn diagrams of the unique and common DEGs among the three libraries. (B-D) Volcano plot of the identified DEGs in the comparisons of CK vs. HF, CK vs. SF, and SF vs. HF. 
Table 3. The number of differential expression gene in Dendrobium officinale.

\begin{tabular}{cccc}
\hline DEG Set & All DEG & Up-Regulated & Down-Regulated \\
\hline CK1_CK2_CK3_vs._HF1_HF2_HF3 & 1944 & 1358 & 586 \\
CK1_CK2_CK3_vs._SF1_SF2_SF3 & 1758 & 932 & 826 \\
SF1_SF2_SF3_vs._HF1_HF2_HF3 & 475 & 417 & 58
\end{tabular}

DEG Set: differential expression gene set name; All DEG: number of differentially expressed genes; up-regulated: number of up-regulated genes; down-regulated: number of down-regulated genes.

\subsection{Functional Annotation and Enrichment of DEGS}

In this study, we annotated the DEGs in the SF vs. HF group using Swiss-Prot, $\mathrm{Nr}$, Pfam, KOG, GO, KEGG, and COG databases to find SI-related genes. To explore the role of DEGs, we conducted the GO term classification analysis based on sequence homology and COG function (Figure 3, Table 4), and KEGG pathway enrichment analysis of the DEGs in the SF vs. HF group. DEGs were functionally classified to understand their biological functions.

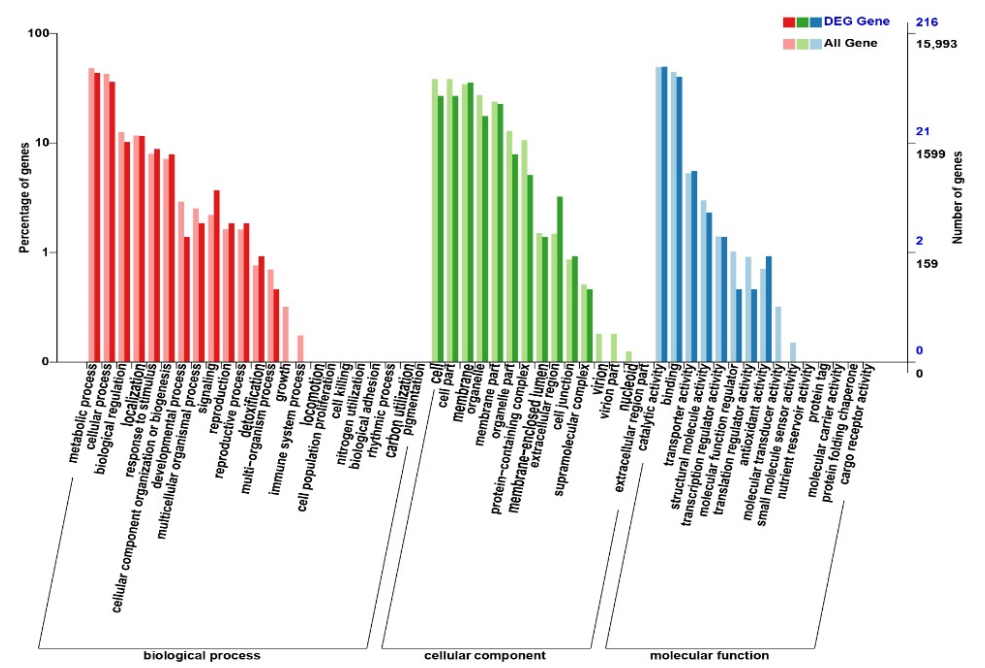

Figure 3. The GO terms classification of all gene and DEGS in SF vs. HF. The annotated genes are divided into three functional GO categories: biological process (BP), cellular component (CC), and molecular function (MF).

Table 4. The number of total genes and number of DEGS of GO term in SF vs. HF.

\begin{tabular}{cccc}
\hline GO Classify & All Gene & DEG Gene & Ratio \\
\hline extracellular region & 238 & 7 & 0.0294 \\
signaling & 352 & 8 & 0.0227 \\
antioxidant activity & 113 & 2 & 0.0177 \\
detoxification & 122 & 2 & 0.0164 \\
reproductive process & 259 & 4 & 0.0154 \\
reproduction & 261 & 4 & 0.0153 \\
response to stimulus & 1275 & 19 & 0.0149 \\
cellular component organization or biogenesis & 1146 & 17 & 0.0148 \\
cell junction & 138 & 2 & 0.0145 \\
transporter activity & 845 & 12 & 0.0142 \\
membrane & 5497 & 77 & 0.0140 \\
catalytic activity & 7876 & 107 & 0.0136 \\
Total gene & 15,993 & 216 & 0.0135 \\
localization & 224 & 3 & 0.0134 \\
transcription regulator activity & 1869 & 25 & 0.0134 \\
\hline
\end{tabular}


Table 4. Cont.

\begin{tabular}{|c|c|c|c|}
\hline GO Classify & All Gene & DEG Gene & Ratio \\
\hline membrane part & 3812 & 49 & 0.0129 \\
\hline membrane-enclosed lumen & 240 & 3 & 0.0125 \\
\hline binding & 7089 & 87 & 0.0123 \\
\hline supramolecular complex & 82 & 1 & 0.0122 \\
\hline metabolic process & 7732 & 94 & 0.0122 \\
\hline cellular process & 6833 & 78 & 0.0114 \\
\hline biological regulation & 2010 & 22 & 0.0109 \\
\hline structural molecule activity & 478 & 5 & 0.0105 \\
\hline multicellular organismal process & 404 & 4 & 0.0099 \\
\hline cell part & 6115 & 58 & 0.0095 \\
\hline cell & 6127 & 58 & 0.0095 \\
\hline multi-organism process & 112 & 1 & 0.0089 \\
\hline organelle & 4386 & 38 & 0.0087 \\
\hline organelle part & 2062 & 17 & 0.0082 \\
\hline translation regulator activity & 146 & 1 & 0.0068 \\
\hline protein-containing complex & 1693 & 11 & 0.0065 \\
\hline developmental process & 466 & 3 & 0.0064 \\
\hline molecular function regulator & 163 & 1 & 0.0061 \\
\hline nucleoid & 20 & 0 & 0 \\
\hline virion & 29 & 0 & 0 \\
\hline extracellular region part & 11 & 0 & 0 \\
\hline virion part & 29 & 0 & 0 \\
\hline protein tag & 3 & 0 & 0 \\
\hline cargo receptor activity & 1 & 0 & 0 \\
\hline protein folding chaperone & 2 & 0 & 0 \\
\hline nutrient reservoir activity & 9 & 0 & 0 \\
\hline molecular transducer activity & 51 & 0 & 0 \\
\hline molecular carrier activity & 3 & 0 & 0 \\
\hline small molecule sensor activity & 24 & 0 & 0 \\
\hline cell killing & 4 & 0 & 0 \\
\hline immune system process & 28 & 0 & 0 \\
\hline cell population proliferation & 5 & 0 & 0 \\
\hline carbon utilization & 2 & 0 & 0 \\
\hline nitrogen utilization & 4 & 0 & 0 \\
\hline biological adhesion & 3 & 0 & 0 \\
\hline growth & 51 & 0 & 0 \\
\hline locomotion & 10 & 0 & 0 \\
\hline pigmentation & 2 & 0 & 0 \\
\hline rhythmic process & 3 & 0 & 0 \\
\hline
\end{tabular}

Here, we found that all DEGs were grouped into 53 functional terms in GO terms, and could be classified into the following functional GO categories: cellular component (CC), biological process (BP), and molecular function (MF). For the groups $\mathrm{CK}$ vs. $\mathrm{SF}$ and $\mathrm{CK}$ vs. $\mathrm{HF}, 813$ and 815 DEGs were assigned to the GO terms, respectively (Supplementary Figure $\mathrm{S} 5 \mathrm{~A}, \mathrm{~B})$. However, in the group SF vs. HF, only 216 DEGs were assigned to the GO term (Figure 3). In all three groups, the two most abundant terms "metabolic process (48.35\%)" and "catalytic activity (49.25\%)" were identical. For CC, these terms were "cell (38.31\%)" and "cell part (38.24\%)". For BP, the two most abundant terms were "metabolic process $(48.35 \%)$ " and "cellular process $(42.72 \%)$ " included cation transport, cell wall organization, glycolytic process through fructose-6-phosphate, fatty acid biosynthetic process, fructose 6-phosphate metabolic process, abscisic acid-activated signaling pathway, and nucleosome assembly (Figure $4 \mathrm{~A})$. For MF, the terms were "catalytic activity $(49.25 \%)$ " and "binding $(44.33 \%)$ )" (Figure 3 ) included phosphatidylinositol phosphate kinase activity, hydrolase activity, esterolysis, protein domain specific binding, 6-phosphofructokinase activity, metal ion binding, peptidase activity, protein heterodimerization activity, and oxidoreductase activity (Figure 4A). This study speculated that after self-pollination, various metabolic 
pathways and biological regulatory processes in D. officinale were affected to varying degrees, which further affected the expression of mRNA and target genes regulated by mRNA (Table 4).

\section{The Most enriched GO Terms}

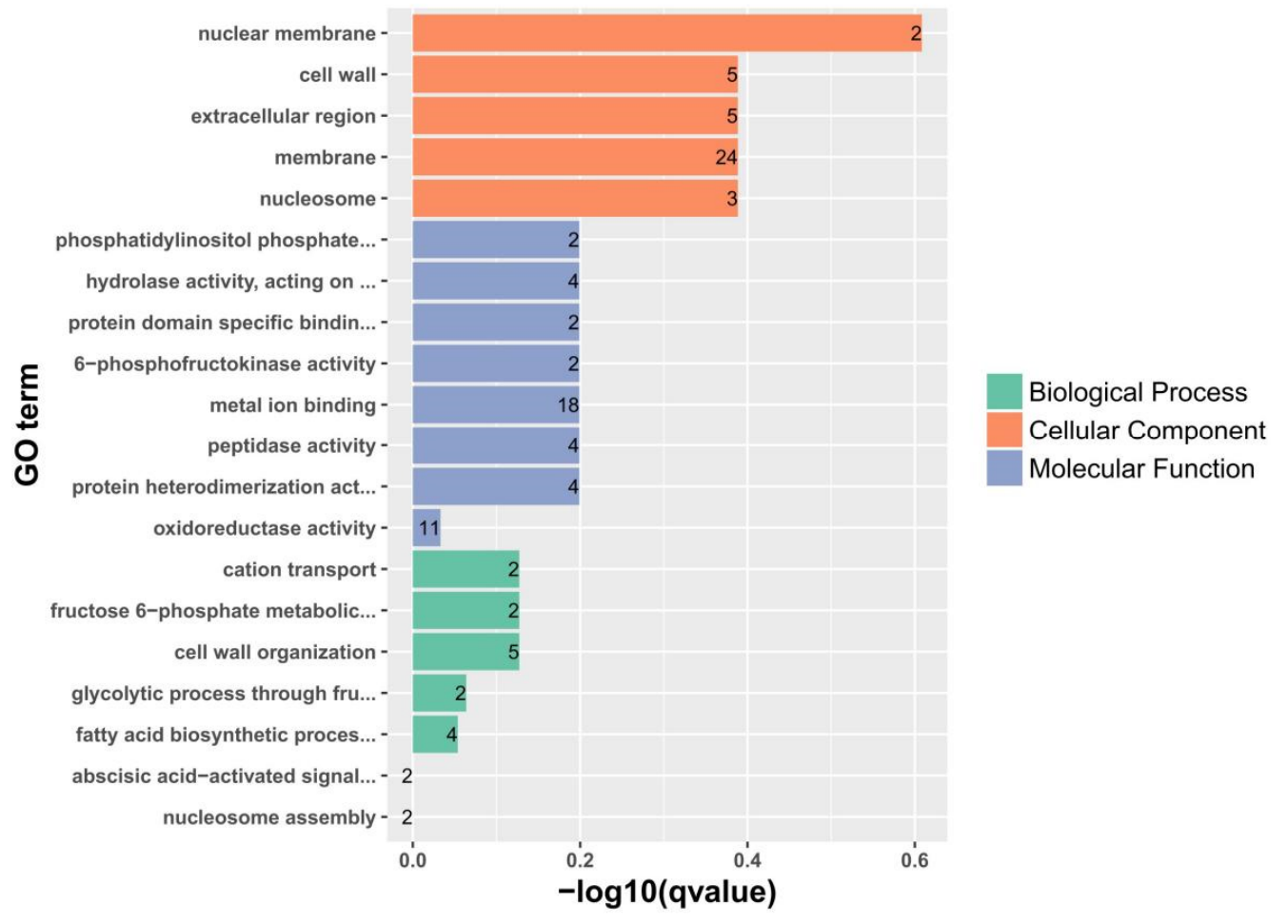

(A)

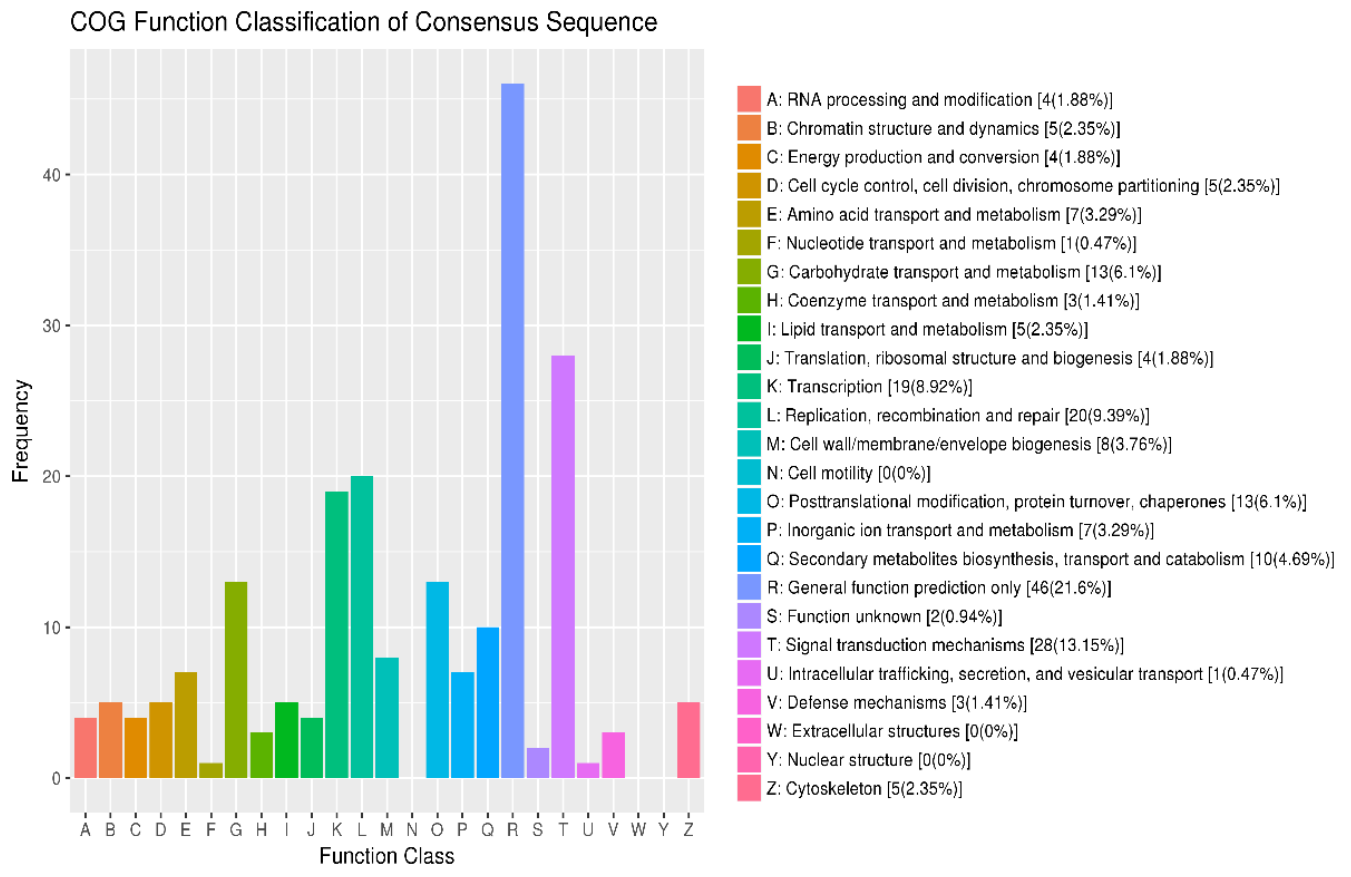

(B)

Figure 4. Cont. 


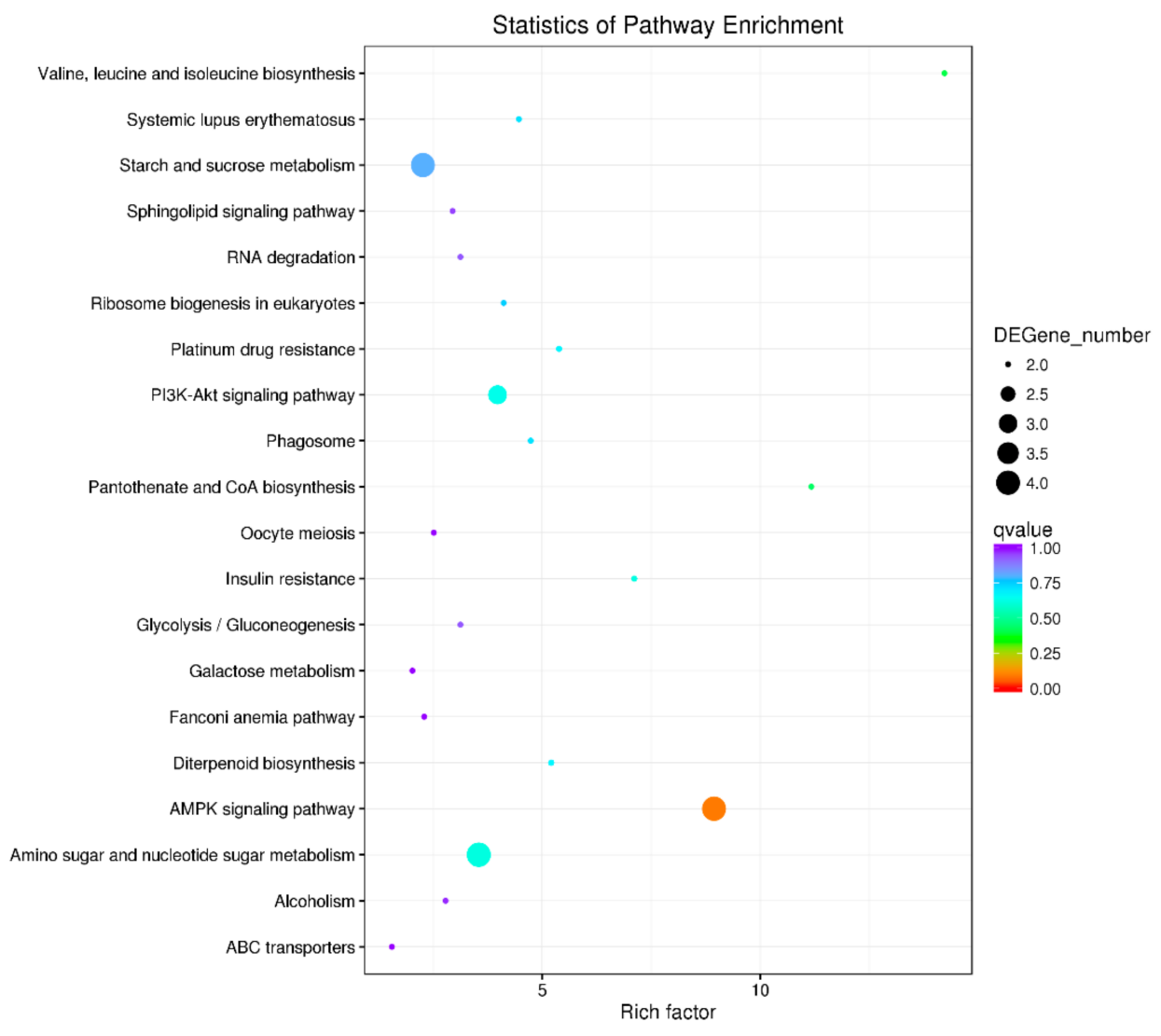

(C)

Figure 4. Analysis of functional classification and enrichment of DEGS in SF vs. HF. (A) The top 20 most enriched GO terms of DEGS in SF vs. HF. (B) The COG function classification of DEGS in SF vs. HF. (C) The top 20 most enriched KEGG pathways of DEGS in SF vs. HF. PI3K (Phosphatidylinositol-3-kinase), AKT (Silk/threonine protein kinase), COA (coenzyme A), AMPK (Adenosine Monophosphate Activated Protein Kinase), ABC (ATP-binding cassette).

In COG database, 213 differentially expressed genes were successfully annotated and classifified into 22 function classes. Among them, sequences involved in general function prediction only (21.6\%); signal transduction mechanisms (13.15\%); replication, recombination and repair $(9.39 \%)$; transcription $(8.92 \%)$; carbohydrate transport and metabolism and posttranslation modiication, protein trun over, chaperones were highly expressed (Figure 4B).

Moreover, KEGG pathway enrichment of the DEGS was also analyzed in this study. In the KEGG database, 50 differentially expressed genes were annotated and enriched into 98 pathways. Among them, a total of 33 pathways were obviously enriched. Figure $4 \mathrm{C}$ shows that the top 20 most enriched pathways, including valine, leucine, and isoleucine biosynthesis; systemic lupus erythematosus; starch and sucrose metabolism; sphingolipid signaling pathway and RNA degradation and so on (Figure 4C).

In the above three function enrichment, some particular pathways were observed, such as cation transport, metal ion binding, RNA degradation, and signal transduction mechanisms. Additionally, fatty acid biosynthetic process, transcription, and unknown pathway were identified. These pathways may be associated with self-incompatibility. So it is necessary to conduct further research on the genes related to these pathways and find candidate genes related to self-incompatibility.

\subsection{Identification of Candidate Genes Associated with Self-Incompatibility}

We selected some SI-related candidate genes from $D$. officinale based on the function and protein of annotated DEGs identified in the SF vs. HF group. Forty-one SI-related 
candidate genes were identified from DEGs (Table 5). Among these, six calcium ion sensor proteins were identified, including four calmodulin-like protein (CML), one calciumdependent protein kinase (CPK), and one calcineurin B-like protein (CBL). For instance, DoLRX4 protein was found to facilitate rapid pollen tube wall growth. Lectin receptorlike kinases (Lectin RLKs) possess an extracellular lectin-like domain. Additionally, four ARC-related genes, eleven SRK-related genes, two Exo70 family genes, nine ubiquitinrelated genes, one fatty acid-related genes, and six amino-acid-related genes were identified (Table 5).

Table 5. The candidate genes associated with self-incompatibility from DEGS in SF vs. HF.

\begin{tabular}{|c|c|c|c|c|}
\hline Gene Name & ID & Description & $\begin{array}{c}\text { Regulated } \\
\left(\log _{2} \text { FC) }\right.\end{array}$ & References \\
\hline DoCML11 & Dendrobium_GLEAN_10039171 & Calmodulin-like protein 11 & $\begin{array}{c}\mathrm{Up} \\
(3.59)\end{array}$ & {$[36]$} \\
\hline DoCML14 & Dendrobium_GLEAN_10057311 & Putative calcium-binding protein CML14 & $\begin{array}{l}\mathrm{Up} \\
(2.77)\end{array}$ & {$[36]$} \\
\hline DoCML10 & Dendrobium_GLEAN_10061210 & Probable calcium-binding protein CML10 & $\begin{array}{l}\mathrm{Up} \\
(2.61)\end{array}$ & [36] \\
\hline DoCML42 & Dendrobium_GLEAN_10078224 & Calcium-binding protein CML42 & $\begin{array}{l}\mathrm{Up} \\
(2.55)\end{array}$ & [36] \\
\hline DoCPK20 & Dendrobium_GLEAN_10069252 & Calcium-dependent protein kinase 20 & $\begin{array}{l}\mathrm{Up} \\
(2.17)\end{array}$ & [37] \\
\hline DoCBL7 & Dendrobium_GLEAN_10021981 & Calcineurin B-like protein 7 & $\begin{array}{l}\text { Down } \\
(-1.67)\end{array}$ & {$[38]$} \\
\hline DoLRX4 & Dendrobium_GLEAN_10140109 & $\begin{array}{l}\text { Pollen-specific leucine-rich repeat } \\
\text { extensin-like protein } 4\end{array}$ & $\mathrm{Up}_{(2.81)}$ & [39] \\
\hline DoL-RLKs1 & Dendrobium_GLEAN_10110992 & $\begin{array}{l}\text { L-type lectin-domain containing receptor } \\
\text { kinase IX.1 }\end{array}$ & $\begin{array}{l}\mathrm{Up} \\
(2.29)\end{array}$ & [40] \\
\hline DoARC12 & Dendrobium_GLEAN_10051179 & U-box domain-containing protein 12 & $\begin{array}{l}\mathrm{Up} \\
(2.35)\end{array}$ & [23] \\
\hline DoARC52 & Dendrobium_GLEAN_10116227 & U-box domain-containing protein 52 & $\begin{array}{l}\mathrm{Up} \\
(2.25)\end{array}$ & [23] \\
\hline DoARC15 & Dendrobium_GLEAN_10032857 & U-box domain-containing protein 15 & $\begin{array}{l}\mathrm{Up} \\
(2.18)\end{array}$ & [23] \\
\hline DoARC3 & Dendrobium_GLEAN_10017335 & U-box domain-containing protein 3 & $\begin{array}{l}\mathrm{Up} \\
(2.25)\end{array}$ & [23] \\
\hline DoSRK1 & Dendrobium_GLEAN_10067876 & $\begin{array}{l}\text { Putative inactive leucine-rich repeat } \\
\text { receptor-like protein kinase }\end{array}$ & $\begin{array}{l}\mathrm{Up} \\
(2.68)\end{array}$ & {$[21,22]$} \\
\hline DoSRK2 & Dendrobium_GLEAN_10005387 & $\begin{array}{l}\text { CBL-interacting serine/threonine-protein } \\
\text { kinase } 12\end{array}$ & $\begin{array}{l}\mathrm{Up} \\
(2.43)\end{array}$ & {$[21,22]$} \\
\hline DoSRK3 & Dendrobium_GLEAN_10113311 & serine/threonine-protein kinase D6PKL2 & $\begin{array}{l}\mathrm{Up} \\
(2.78)\end{array}$ & {$[21,22]$} \\
\hline DoSRK4 & Dendrobium_GLEAN_10042125 & $\begin{array}{l}\text { CBL-interacting serine/threonine-protein } \\
\text { kinase } 12\end{array}$ & $\begin{array}{l}\mathrm{Up} \\
(2.62)\end{array}$ & {$[21,22]$} \\
\hline DoSRK5 & Dendrobium_GLEAN_10128039 & serine/threonine-protein kinase BLUS1 & $\begin{array}{l}\mathrm{Up} \\
(2.13)\end{array}$ & {$[21,22]$} \\
\hline DoSRK6 & Dendrobium_GLEAN_10027995 & Putative serine/threonine-protein kinase & $\begin{array}{l}\mathrm{Up} \\
(2.03)\end{array}$ & {$[21,22]$} \\
\hline DoSRK7 & Dendrobium_GLEAN_10098521 & Serine/threonine-protein kinase PBS1 & $\begin{array}{l}\mathrm{Up} \\
(1.86)\end{array}$ & {$[21,22]$} \\
\hline $\operatorname{DoSRK} 8$ & Dendrobium_GLEAN_10000384 & $\begin{array}{l}\text { CBL-interacting serine/threonine-protein } \\
\text { kinase } 12\end{array}$ & $\begin{array}{l}\mathrm{Up} \\
(2.43)\end{array}$ & {$[21,22]$} \\
\hline DoSRK9 & Dendrobium_GLEAN_10010756 & $\begin{array}{l}\text { Leucine-rich repeat receptor-like } \\
\text { serine/threonine-protein kinase }\end{array}$ & $\begin{array}{l}\mathrm{Up} \\
(2.06)\end{array}$ & {$[21,22]$} \\
\hline DoSRK10 & Dendrobium_GLEAN_10047407 & $\begin{array}{l}\text { Receptor-like serine/threonine-protein } \\
\text { kinase ALE2 }\end{array}$ & $\begin{array}{l}\text { Down } \\
(-1.32)\end{array}$ & {$[21,22]$} \\
\hline DoSRK11 & Dendrobium_GLEAN_10044962 & $\begin{array}{l}\text { Putative LRR receptor-like } \\
\text { serine/threonine-protein kinase RLK }\end{array}$ & $\begin{array}{l}\mathrm{Up} \\
(2.41)\end{array}$ & {$[21,22]$} \\
\hline
\end{tabular}


Table 5. Cont.

\begin{tabular}{|c|c|c|c|c|}
\hline Gene Name & ID & Description & $\begin{array}{c}\text { Regulated } \\
\left(\log _{2} F C\right)\end{array}$ & References \\
\hline DoEXO1 & Dendrobium_GLEAN_10047257 & Exocyst complex component EXO70B1 & $\begin{array}{l}\mathrm{Up} \\
(2.68)\end{array}$ & {$[24,25]$} \\
\hline DoEXO2 & Dendrobium_GLEAN_10108122 & Exocyst complex component EXO70B1 & $\begin{array}{l}\mathrm{Up} \\
(2.83)\end{array}$ & {$[24,25]$} \\
\hline DoEBI1 & Dendrobium_GLEAN_10013195 & E3 ubiquitin-protein ligase WAV3 & $\begin{array}{l}\mathrm{Up} \\
(2.24)\end{array}$ & [27] \\
\hline DoEBI2 & Dendrobium_GLEAN_10030613 & E3 ubiquitin-protein ligase RGLG4 & $\begin{array}{l}\mathrm{Up} \\
(2.13)\end{array}$ & [27] \\
\hline DoEBI3 & Dendrobium_GLEAN_10106149 & E3 ubiquitin-protein ligase SPL2 & $\mathrm{Up}_{(1.62)}$ & [27] \\
\hline DoEBI4 & Dendrobium_GLEAN_10029117 & E3 ubiquitin-protein ligase KEG & $\begin{array}{l}\mathrm{Up} \\
(2.49)\end{array}$ & [27] \\
\hline DoEBI5 & Dendrobium_GLEAN_10062294 & $\begin{array}{l}\text { Ubiquitin-like protein-NEDD8-like } \\
\text { protein RUB3 }\end{array}$ & $\begin{array}{c}\mathrm{Up} \\
(3.09)\end{array}$ & [27] \\
\hline DoEBI6 & Dendrobium_GLEAN_10032857 & Ring-type E3 ubiquitin transferase & $\begin{array}{l}\mathrm{Up} \\
(2.18)\end{array}$ & [27] \\
\hline DoEBI7 & Dendrobium_GLEAN_10126475 & E3 ubiquitin-protein ligase XBAT31 & $\begin{array}{l}\mathrm{Up} \\
(2.07)\end{array}$ & [27] \\
\hline DoEBI8 & Dendrobium_GLEAN_10076237 & $\begin{array}{l}\text { Probable BOI-related E3 ubiquitin-protein } \\
\text { ligase } 3\end{array}$ & $\begin{array}{l}\mathrm{Up} \\
(2.47)\end{array}$ & [27] \\
\hline DoEBI9 & Dendrobium_GLEAN_10069672 & BOI-related E3 ubiquitin-protein ligase 1 & $\begin{array}{l}\mathrm{Up} \\
(2.43)\end{array}$ & [27] \\
\hline DoFAT1 & Dendrobium_GLEAN_10055554 & omega- 6 fatty acid desaturase & $\begin{array}{l}\mathrm{Up} \\
(2.34)\end{array}$ & [27] \\
\hline DoAMI1 & Dendrobium_GLEAN_10138041 & Serine carboxypeptidase-like 35 & $\begin{array}{l}\mathrm{Up} \\
(2.31)\end{array}$ & [27] \\
\hline DoAMI2 & Dendrobium_GLEAN_10118990 & Amino-acid permease BAT1 like & $\begin{array}{l}\text { Down } \\
(-2.86)\end{array}$ & [27] \\
\hline DoAMI3 & Dendrobium_GLEAN_10033197 & Aspartokinase 1 & $\begin{array}{c}\mathrm{Up} \\
(1.57)\end{array}$ & [27] \\
\hline DoAMI4 & Dendrobium_GLEAN_10141386 & $\begin{array}{c}\text { Arogenate dehydratase/prephenate } \\
\text { dehydratase } 2\end{array}$ & $\begin{array}{c}\mathrm{Up} \\
(2.21)\end{array}$ & [27] \\
\hline DoAMI5 & Dendrobium_GLEAN_10014762 & $\begin{array}{c}\text { Probable polyamine transporter } \\
\text { At3g19553 }\end{array}$ & $\begin{array}{l}\mathrm{Up} \\
(3.17)\end{array}$ & [27] \\
\hline DoAMI6 & Dendrobium_GLEAN_10056253 & amino acid transporter & $\mathrm{Up}_{(1.53)}$ & [27] \\
\hline
\end{tabular}

\section{6. $q R T-P C R$ Validate Analysis of DEGs}

We randomly selected 16 DEGs (10 up-regulated and 6 down-regulated) in the SF vs. HF group for qRT-PCR analysis to evaluate the precision of transcriptome sequencing. The comparative expression of SF and HF was used to compare between RNA-seq and qRT-PCR. Here, the regulatory trends of 16 selected DEGs in RNA-seq and qRT-PCR were roughly the same (Figure 5). The qRT-PCR result indicated that the DEGs of transcriptome sequencing data were reliable. 


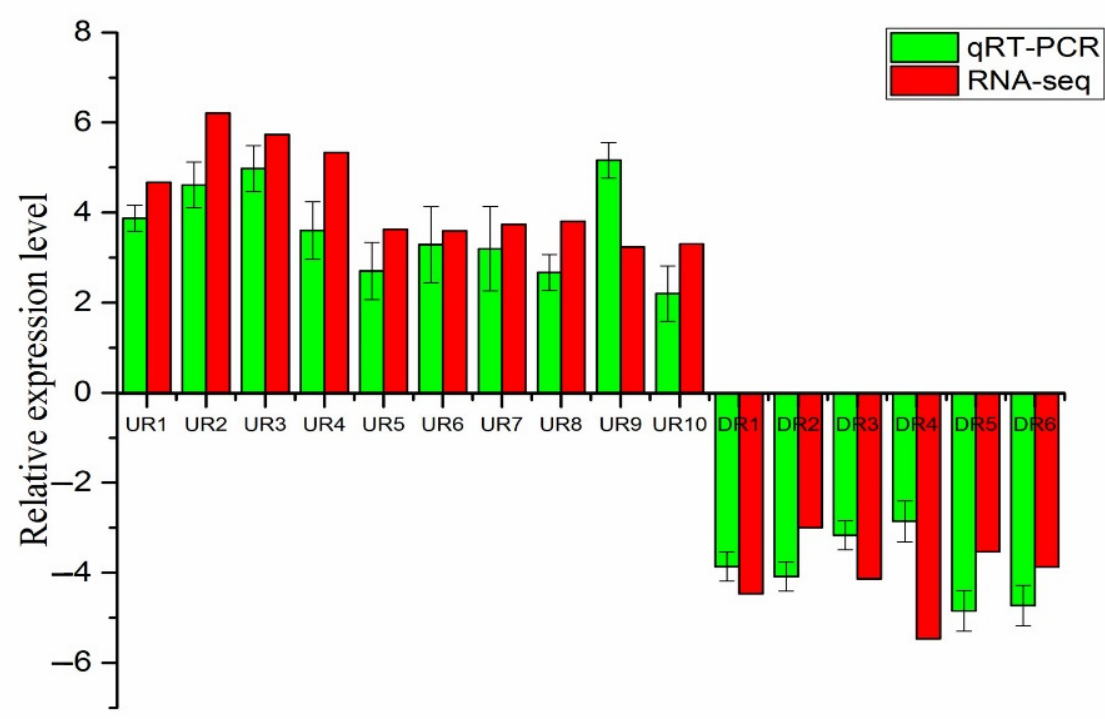

Figure 5. Validation of RNA-seq data by qRT-PCR analysis. X-axis: gene name, Y-axis: the relative expression level was expressed as $\log _{2}$ (fold change) in gene expression. The relative expression of 16 random genes, were determined by RT-qPCR (green column) and compared with the results of RNA-seq (red column). Error bars represented standard deviation (SD). UR (up-regulated genes), DR (down-regulated genes).

\section{Discussion}

Previous research showed that gametophyte self-incompatibility indicated that pollen could invade the stigma after germination on the stigma, and could extend for a section in the style tissue, and then was inhibited. However, sporophytic self-incompatibility indicated that pollen falls on the stigma and fails to germinate normally, or it wraps around the stigma papillary cells after germination but cannot invade the stigma [41,42]. In this study, the microscopic observation showed that the pollen tubes could grow in the style at $2 \mathrm{~h}$ after self-pollination and cross-pollination, but most of the pollen tubes stopped growing at $4 \mathrm{~h}$ after self-pollination and some pollen tubes had disappeared at $8 \mathrm{~h}$ after selfpollination (Figure 1), consistent with results of previous studies [43]. Studied on pollen tube germination in D. officinale showed that SI response after self-pollination initiated in a short time with less than $4 \mathrm{~h}$. The results indicated that self-incompatibility of $D$. officinale may be gametophyte self-incompatibility, while the specific SI types still need to be verified by molecular biological evidence.

The studies on SI of Citrus reticulata had shown that SI-related candidate genes acted by regulating pollen development, the ubiquitin pathway, signaling pathways, gibberellin stimulus, receptor kinases, calcium ion binding, and transcription [44,45]. Here, we detected that cation transport, metal ion binding, RNA degradation, and signal transduction mechanisms (Figure 4) were associated with SI. The expression of Lectin RLKs was upregulated in the HF group (Table 5). Wan et al. (2008) [40] showed that male sterility in Arabidopsis was due to mutation in one Lectin RLK gene. So Lectin RLKs may play an important role in cross-pollination of D. officinale. DoLRX4 levels that were also up-regulated in HF (Table 5). DoLRX4 similar to LRX(ZmPEX1) was specifically expressed in Zea Mays pollen. ZmPEX1 is known to be located in the inner wall of pollen grains and callose sheath of the pollen tube. Studies have substantiated the role of ZmPEX1 in reproduction, which implies that it may be involved in the precipitation of structural units during the rapid growth of the pollen tube wall, or it may act as a sex recognition signal molecule interacting with the pistillate [39].

Calcium ion sensor proteins, an important class of proteins, are involved in several signaling pathways in plants [46]. Here, six calcium ion sensor proteins, including four CML protein, one CPK, and one CBL were identified from DEGs, and these proteins have 
been previously identified and found to be related to SI in Brassica [36-38,47]. Additionally, the expression of some CaM/CML (Calmodulin/calmodulin-like) genes has been demonstrated in A. thaliana during pollen germination and tube growth [48]. Thus, calcium ion sensor proteins, may play an important regulatory role in the SI of $D$. officinale.

Here, four ARC-related genes, eleven SRK, and two Exo70 family genes were identified from DEGs (SF vs. HF). ARC1 is known to bind to activated SRK, followed by phosphorylation, which results in the degradation of EXO70A1 [20,21]. Ubiquitin is a proteolytic degradation marker and it is hypothesized that the activation of SI responses might be dependent on a phosphorylation-mediated ubiquitination mechanism [49,50]. Also, the ubiquitination mechanism is the key regulator of the S-RNase-based GSI [51]. Besides, we also found some genes for amino acid metabolism (Figure 4, Table 5). The proteins produced by these genes act as critical enzymes that convert glutamate to glutamine, which facilitates the assimilation of ammonia into glutamine for its transport in plants [52,53]. Additionally, glutamate is a $\gamma$-aminobutyrate precursor, which regulates pollen tube growth [54].

In conclusion, some genes that may play a role in SI of $D$. officinale have been discovered in our research, including $\mathrm{Ca}^{2+}$ signal genes, $A R C$ related genes, $S R K$ related genes, Exo70 family genes, ubiquitin-related genes, fatty acid-related genes, amino acid-related genes, $L R X$-related genes and RLKs-related genes. This result provides some candidate genes to research the specific mechanism of SI in D. officinale.

Supplementary Materials: The following are available online at https:/ / www.mdpi.com/2073-442 5/12/3/432/s1, Table S1.: The Sequences of primer for qRT-PCR validate analysis; Figure S1.: Pearson correlation of all samples; Figure S2.: Heat map of gene expressions in the three libraries with three replicates; Figure S3.: The number of the unigenes annotated in the databases; Figure S4. The number of the identified DEGs in the three libraries; Figure S5.: The GO terms classification of all gene and DEGS. (A) GO classification annotation in CK1_CK2_CK3_vs._SF1_SF2_SF3. (B) GO classification annotation in CK1_CK2_CK3_vs._HF1_HF2_HF3.

Author Contributions: Y.C.: conceptualization, resources, investigation, methodology, writingreview and editing, supervision, project administration. B.H.: investigation, methodology, formal analysis, writing-original draft. F.Z.: methodology, supervision. X.L.: resources, methodology. J.X.: conceptualization, resources, methodology, writing-review and editing, supervision, project administration. All authors have read and agreed to the published version of the manuscript.

Funding: This research was Supported by Major projects of key research programs in Jiangxi Province (Grant No.: 20192ACB60013; 20171ACF60017), awarded to Pro. Jiangkun Xie; the Natural Science Foundation of China (Grant No.: 31800640) and Young talents of Jiangxi Normal University, awarded to PhD. Yaling Chen.

Conflicts of Interest: The authors declare that they have no conflict of interest.

\section{References}

1. Meng, L.Z.; Lv, G.P.; Hu, D.J.; Cheong, K.L.; Xie, J.; Zhao, J. Effects of polysaccharides from different species of Dendrobium (Shihu) on macrophage function. Molecules 2013, 18, 5779-5791. [CrossRef]

2. Yan, L.; Wang, X.; Liu, H.; Tian, Y.; Lian, J.M.; Yang, R.J.; Hao, S.M.; Wang, X.J.; Yang, S.C.; Li, Q.Y.; et al. The genome of Dendrobium officinale illuminates the biology of the important traditional Chinese orchid herb. Mol. Plant 2015, 8, 922-934. [CrossRef] [PubMed]

3. Huang, K.; Li, Y.; Tao, S.; Wei, G.; Huang, Y.; Chen, D.; Wu, C. Purification, Characterization and Biological Activity of Polysaccharides from Dendrobium officinale. Molecules 2016, 21, 701. [CrossRef]

4. Chen, Y.; Wang, Y.; Lyu, P.; Chen, L.; Shen, C.; Sun, C. Comparative transcriptomic analysis reveal the regulation mechanism underlying MeJA-induced accumulation of alkaloids in Dendrobium officinale. J. Plant Res 2019, 132, 419-429. [CrossRef]

5. Huang, S.; Chen, F.; Cheng, H.; Huang, G. Modification and application of polysaccharide from traditional Chinese medicine such as Dendrobium officinale. Int. J. Biol. Macromol 2020, 157, 385-393. [CrossRef] [PubMed]

6. Liang, J.; Chen, S.; Hu, Y.; Yang, Y.; Yuan, J.; Wu, Y. Protective roles and mechanisms of Dendrobium officinal polysaccharides on secondary liver injury in acute colitis. Int. J. Biol. Macromol. 2018, 107, 2201-2210. [CrossRef] [PubMed]

7. Yue, H.; Liu, Y.; Qu, H.; Ding, K. Structure analysis of a novel heteroxylan from the stem of Dendrobium officinale and antiangiogenesis activities of its sulfated derivative. Int. J. Biol. Macromol. 2017, 103, 533-542. [CrossRef] 
8. Liu, J.; Zhu, T.; Niu, Q.; Yang, X.; Suo, H.; Zhang, H. Dendrobium nobile alkaloids protects against $\mathrm{H} 2 \mathrm{O} 2$-induced neuronal injury by suppressing JAK-STATs pathway activation in N2A cells. Biol. Pharm. Bull. 2020, 43, 716-724. [CrossRef]

9. Devadas, R.; Pattanayak, S.L.; Singh, D.R. Studies on cross compatibility in Dendrobium species and hybrids. Indian J. Genet. 2016, 76, 344-355.

10. Zhang, G.Q.; Xu, Q.; Bian, C.; Tsai, W.C.; Yeh, C.M.; Liu, K.W.; Yoshida, K.; Zhang, L.S.; Chang, S.B.; Chen, F.; et al. The Dendrobium catenatum Lindl. genome sequence provides insights into polysaccharide synthase, floral development and adaptive evolution. Sci Rep. 2016, 6, 19029. [CrossRef] [PubMed]

11. Zhu, B.; Yuan, H.; Yu, Q.X.; Si, J.P. Pollen vigor and development of germplasm of Dendrobium officinale. Chin. J. Chin. Mater. Med. 2011, 36, 755-757.

12. Bhattacharyya, P.; Kumaria, S. Molecular characterization of Dendrobium nobile Lindl., an endangered medicinal orchid, based on randomly amplified polymorphic DNA. Plant Syst. Evol. 2015, 301, 201-210. [CrossRef]

13. Bhattacharyya, P.; Ghosh, S.; Mandi, S.S.; Kumaria, S.; Tandon, P. Genetic variability and association of AFLP markers with some important biochemical traits in Dendrobium thyrsiforum, a threatened medicinal orchid. S. Afr. J. Bot. 2017, 109, 214-222. [CrossRef]

14. Yan, S.; Zhao, T.M.; Li, Y.F.; Hu, Y.D.; Chun, Z. Agronomic and quality traits of diferent Dendrobium nobile in Hejiang. Chin. J. Exp. Tradit Med. Formulae 2018, 24, 73-77.

15. Igic, B.; Kohn, J.R. Evolutionary relationships among self-incompatibility RNases. Proc. Natl. Acad. Sci. USA 2001, 98, 13167-13171. [CrossRef] [PubMed]

16. Doucet, J.; Lee, H.K.; Goring, D.R. Pollen acceptance or rejection: A tale of two pathways. Trends Plant Sci. 2016, 21, 1058-1067. [CrossRef]

17. Mcclure, B.A.; Franklin-Tong, V. Gametophytic self-incompatibility: Understanding the cellular mechanisms involved in "self" pollen tube inhibition. Planta 2006, 224, 233-245. [CrossRef] [PubMed]

18. Fujii, S.; Kubo, K.; Takayama, S. Non-self- and self-recognition models in plant self-incompatibility. Nat. Plants 2016, 2, 16130. [CrossRef] [PubMed]

19. McClure, B.A.; Gray, J.E.; Anderson, M.A.; Clarke, A.E. Self-incompatibilityin Nicotiana alata involves degradation of pollen rRNA. Nature 1990, 347, 757-760. [CrossRef]

20. de Graaf, B.H.J.; Rudd, J.J.; Wheeler, M.J.; Perry, R.M.; Bell, E.M.; Osman, K.; Franklin, F.C.H.; Franklin-Tong, V.E. Selfincompatibility in Papaver targets soluble inorganic pyrophosphatases in pollen. Nature 2006, 444, 490-493. [CrossRef] [PubMed]

21. Samuel, M.A.; Chaal, B.K.; Lampard, G.; Green, B.R.; Ellis, B. Surviving the passage: Non-canonical stromal targeting of an Arabidopsis mitogen-activated protein kinase kinase. Plant Signal Behav. 2008, 3, 6-12. [CrossRef]

22. Samuel, M.A.; Mudgil, Y.; Salt, J.N.; Delmas, F.; Ramachandran, S.; Chilelli, A.; Goring, D.R. Interactions between the S-Domain receptor kinases and AtPUB-ARM E3 ubiquitin ligases suggest a conserved signaling pathway in Arabidopsis. Plant Physiol. 2008, 147, 2084-2095. [CrossRef] [PubMed]

23. Haasen, K.E.; Goring, D.R. The recognition and rejection of self-incompatible pollen in the Brassicaceae. Bot. Stud. 2010, 51, 1-6.

24. Bower, M.S.; Matias, D.D.; Fernandes-Carvalho, E.; Mazzurco, M.; Gu, T.; Rothstein, S.J.; Goring, D.R. Two members of the thioredoxin-h family interact with the E. kinase domain of a Brassica S locus receptor kinase. Plant Cell 1996, 8, 1641-1650.

25. Samuel, M.A.; Chong, Y.T.; Haasen, K.E.; Aldea-Brydges, M.G.; Stone, S.L.; Goring, D.R. Cellular pathways regulating responses to compatible and self-incompatible pollen in Brassica and Arabidopsis stigmas intersect at Exo70A1, a putative component of the exocyst complex. Plant Cell 2009, 21, 2655-2671. [CrossRef] [PubMed]

26. Lao, X.; Suwabe, K.; Niikura, S.; Kakita, M.; Iwano, M.; Takayama, S. Physiological and genetic analysis of CO2-induced breakdown of self-incompatibility in Brassica rapa. J Exp Bot. 2014, 65, 939-951. [CrossRef]

27. Wang, W.; Yu, H.; Li, T.; Li, L.; Zhang, G.; Liu, Z.; Huang, T.; Zhang, Y. Comparative proteomics analyses of pollination response in endangered orchid species Dendrobium Chrysanthum. Int. J. Mol. Sci. 2017, 18, 2496. [CrossRef] [PubMed]

28. Xie, J.k.; Zuo, J.H.; Huang, Y.H.; Li, C.S.; Chen, Y.L. The origin and germplasm collection for cultivated Dendrobium officinale K. Kimura \& Migo individuals revealed by EST-SSR markers. Genet. Resour. Crop Evol. 2020, 67, 1209-1219.

29. Tian, C.X.; Zhang, Y.M.; Ma, H.L. Primary study on preparation procedure of paraffin section with embryo structure of Poa pratensis. Pratacultural Sci. 2013, 30, 1980-1986.

30. Trapnell, C.; Williams, B.; Pertea, G.; Mortazavi, A.; Kwan, G.; Baren, M.; Salzberg, S.; Wold, B.; Pachter, L. Transcript assembly and quantification by RNA-Seq reveals unannotated transcripts and isoform switching during cell differentiation. Nat. Biotechnol. 2010, 28, 511-515. [CrossRef]

31. Anders, S.; Huber, W. Differential expression analysis for sequence count data. Genome biol. 2010, 11, R106. [CrossRef] [PubMed]

32. Wang, C.; Cui, H.M.; Huang, T.H.; Liu, T.K.; Hou, X.L.; Li, Y. Identification and validation of reference genes for RT-qPCR analysis in non-heading Chinese cabbage flowers. Front. Plant Sci. 2016, 7, 811. [CrossRef] [PubMed]

33. Livak, K.J.; Schmittgen, T.D. Analysis of relative gene expression data using real time quantitative PCR and the $2^{-\Delta \Delta C T}$ method. Methods 2001, 25, 402-408. [CrossRef]

34. Hansen, K.D.; Wu, Z.J.; Irizarry, R.A.; Leek, J.T. Sequencing technology does not eliminate biological variability. Nat Biotechnol. 2011, 29, 572-573. [CrossRef] [PubMed]

35. Schulze, S.K.; Kanwar, R.; Golzenleuchter, M.; Therneau, T.M.; Beutler, A.S. SERE: Single-parameter quality control and sample comparison for RNA-Seq. BMC Genomics 2012, 13, 524. [CrossRef] 
36. Nie, S.S.; Zhang, M.J.; Zhang, L.G. Genome-wide identification and expression analysis of calmodulin-like $(C M L)$ genes in Chinese cabbage (Brassica rapa L. ssp. pekinensis). BMC Genomics 2017, 18, 482. [CrossRef]

37. Wu, P.; Wang, W.; Duan, W.; Li, Y.; Hou, X. Comprehensive analysis of the CDPK-SnRK superfamily genes in Chinese cabbage and its evolutionary implications in plants. Front. Plant Sci. 2017, 8, 162. [CrossRef] [PubMed]

38. Mohanta, T.K.; Kumar, P.; Bae, H.H. Genomics and evolutionary aspect of calcium signaling event in calmodulin and calmodulinlike proteins in plants. BMC Plant Biol. 2017, 17, 38. [CrossRef]

39. Rubinstein, A.L.; Broadwater, A.H.; Lowrey, K.B.; Bedinger, P.A. Pex1, a pollen-specific gene with an extensin-like domain. Proc. Natl. Acad. Sci. USA 1995, 92, 3086-3090. [CrossRef]

40. Wan, J.; Patel, A.; Mathieu, M.; Kim, S.; Xu, D.; Stacey, G. A lectin receptor-like kinase is required for pollen development in Arabidopsis. Plant Mol. Biol. 2008, 67, 469-482. [CrossRef]

41. Wheeler, M.J.; Graaf, B.H.J.; Hadjiosif, N.; Perry, R.M.; Poulter, N.S.; Osman, K.; Vatovec, S.; Harper, A.; Franklin, F.C.H.; Franklin-Tong, V.E. Identification of the pollen self-incompatibility determinant in Papaver rhoeas. Nature 2009, 459, $992-995$. [CrossRef]

42. Millner, H.J.; McCrea, A.R.; Baldwin, T.C. An investigation of self-incompatibility within the genus Restrepia. Am. J Bot. 2015, 102, 487-494. [CrossRef] [PubMed]

43. Gao, Y.; Lin, R.; Yuan, C.; Ma, L.; Wang, J.; Zhu, Y.; Gao, Y. Cytological study on self and hybridization affinity in Dendrobium officinale. J. Zhejiang A F Univ. 2018, 35, 618-623.

44. Miao, H.X.; Qin, Y.H.; Silva, J.A.T.; Ye, Z.X.; Hu, G.B. Identification of differentially expressed genes in pistils from selfincompatible Citrus reticulata by suppression subtractive hybridization. Mol. Biol. Rep. 2013, 40, 159-169. [CrossRef]

45. Miao, H.X.; Qin, Y.H.; Ye, Z.X.; Hu, G.B. Molecular characterization and expression analysis of ubiquitin-activating enzyme E1 gene in Citrus reticulata. Genes 2013, 53, 249-259. [CrossRef]

46. Zhang, W.; Wei, X.; Meng, H.L.; Ma, C.H.; Jiang, N.H.; Zhang, G.H.; Yang, S.C. Transcriptomic comparison of the self-pollinated and cross-pollinated flowers of Erigeron breviscapus to analyze candidate self-incompatibility-associated genes. BMC Plant Biol. 2015, 15, 248. [CrossRef]

47. Jung, H.J.; Kayum, M.A.; Thamilarasan, S.K.; Nath, U.K.; Park, J.I.; Chung, M.Y.; Hur, Y.; Nou, I.S. Molecular characterisation and expression profiling of calcineurin B-like $(C B L)$ genes in Chinese cabbage under abiotic stresses. Funct. Plant Biol. 2017, 44, 739. [CrossRef] [PubMed]

48. Wang, Y.; Zhang, W.Z.; Song, L.F.; Zou, J.J.; Su, Z.; Wu, W.H. Transcriptome analyses show changes in gene expression to accompany pollen germination and tube growth in Arabidopsis. Plant Physiol. 2008, 148, 1201-1211. [CrossRef]

49. Hua, Z.; Kao, T.H. Identification and characterization of components of a putative petunia S-locus F-box-containing E3 ligase complex involved in S-RNase-based self-incompatibility. Plant Cell 2006, 18, 2531-2553. [CrossRef] [PubMed]

50. Vierstra, R.D. The ubiquitin-26S proteasome system at the nexus of plant biology. Nat. Rev. Mol. Cell Biol. 2009, 10, 385-397. [CrossRef] [PubMed]

51. Liu, W.; Fan, J.; Li, J.; Song, Y.; Li, Q.; Zhang, Y.; Xue, Y. SCF (SLF)-mediated cytosolic degradation of S-RNase is required for cross-pollen compatibility in S-RNase-based self-incompatibility in Petunia hybrida. Front. Genet. 2014, 5, 228. [CrossRef] [PubMed]

52. Ma, H. Plant reproduction: GABA gradient, guidance and growth. Curr. Biol. 2003, 13, R834-R836. [CrossRef] [PubMed]

53. Canovas, F.M.; Avila, C.; Canton, F.R.; Canas, R.A.; Torre, F. Ammonium assimilation and amino acid metabolism in conifers. J. Exp. Bot. 2007, 58, 2307-2318. [CrossRef] [PubMed]

54. Palanivelu, R.; Brass, L.; Edlund, A.F.; Preuss, D. Pollen tube growth and guidance is regulated by POP2, an Arabidopsis gene that controls GABA levels. Cell 2003, 114, 47-59. [CrossRef] 